ORIGINAL ARTICLE

\title{
Epidemiology of lower limb fractures in general practice in the United Kingdom
}

\section{J A Kaye, H Jick}

Injury Prevention 2004;10:368-374. doi: 10.1136/ip.2004.005843

See end of article for authors' affiliations

Correspondence to: Dr James A Kaye, Boston Collaborative Drug Surveillance Program, 11 Muzzey Street, Lexington, MA 02421, USA; jkaye@ bu.edu
Study objective: To estimate the incidence of lower limb fractures in the United Kingdom and assess the relative importance of various risk factors for lower limb fractures.

Design: Cohort analysis and matched case-control study.

Setting: General practices contributing information to the General Practice Research Database.

Subjects: Individuals registered with these general practices who were at risk for a first time lower limb fracture from 1 January 1990 to 31 December 2001.

Main outcome measures: Age, sex, and fracture site specific incidence rates; relative risks and population attributable risks for various medical risk factors.

Results: Overall, the risk of lower limb fracture was $17 \%$ higher in women then in men. Within age groups, men and women had generally similar proportions of fractures at specific sites in the lower limb. Among the risk factors evaluated, road collisions were associated with the highest relative risk for lower limb fracture, but only accounted for $3.1 \%$ or less of the population attributable risk for specific fracture types in any age group. The relative risk for lower limb fracture associated with a diagnosis of dementia was 2.3 (95\% confidence interval 2.0 to 2.6 ), while relative risk estimates for other medical diagnoses were less than 2. Fracture risk was increased among current users of corticosteroids, antipsychotics, antidepressants, and hypnotic/sedatives, but the population attributable risks for each of these drug classes within fracture and age specific strata were only $3.0 \%$ or less.

Conclusions: Many risk factors for lower limb fracture have been identified, but population attributable risk estimates for various risk factors are small. These findings suggest that multifactorial prevention programs are needed to decrease the incidence of lower limb fractures in the general population. ower limb fractures account for approximately one third of all fractures and may result in substantial mortality and morbidity. Although the occurrence and prevention of hip fractures have been the subject of many publications, the epidemiology of all lower limb fractures combined has not been studied extensively in the general population of the United Kingdom. Moreover, although many risk factors for lower limb fracture have been reported previously, there is little quantitative information in the literature regarding the independent contribution of medical risk factors to the population burden of lower limb fractures. To address these questions, we carried out a population based study using information from the United Kingdom's General Practice Research Database (GPRD).

\section{METHODS}

The study protocol was approved by the Scientific and Ethical Advisory Group of the GPRD.

\section{Data source and base population}

We conducted this study using data from general practices in the United Kingdom that have contributed data to the GPRD maintained by the Boston Collaborative Drug Surveillance Program (December, 2001 update) and use Vision software (InPractice Systems Ltd, London, UK) to record their patients' medical information. The general practitioners enter demographic and diagnostic data into their computerized medical records, and they use the computer software to record and generate prescriptions, thereby ensuring a complete record of medications prescribed to each patient. Diagnoses are specified using the Read classification system. We have carefully validated the GPRD and used the information it contains to conduct numerous pharmacoepidemiology research studies. ${ }^{12}$ Our group has found that fracture diagnoses recorded in this database are highly reliable and accurate when validated against other information contained in full computer profiles. ${ }^{3}$ Therefore in the present study we analyzed fractures recorded by the general practitioners without undertaking additional validation procedures related to the fracture diagnosis.

The base population included all subjects in 142 general practices actively contributing data to the GPRD maintained by the Boston Collaborative Drug Surveillance Program who were at risk of a first time lower limb fracture during the period from 1 January 1990 to 31 December 2001, and who were registered as permanent members of their general practice or died during the study period. For analyses of incidence rates, person-time was calculated as the sum of days of follow up time stratified by sex, age in years, and calendar time.

\section{Cases}

Cases had a first time diagnosis of lower limb fracture recorded in their computerized medical record at any time during the study period. Each case's index date was the date of the first recorded diagnosis of a lower limb fracture. Fractures were classified by anatomic site as those of the hip, other femoral sites, patella, tibia and/or fibula, ankle, tarsal and/or metatarsal bones, or phalanges of the foot. Seven subjects with fractures at unspecified sites in the lower limb were excluded from the case-control analysis. The median time of follow up in the GPRD for cases was 3.7 years (maximum 11.8 years)

Abbreviations: $\mathrm{Cl}$, confidence interval; GPRD, General Practice Research Database; RR, relative risk 


\section{Controls}

Up to two controls were matched to each case by year of birth (within one year), sex, general practice, index date, and duration of follow up time in the GPRD before the index date (within one year). No eligible control could be identified for 73 cases $(0.2 \%)$; these cases were therefore omitted from the matched case-control analysis. Each case's index date was assigned as the index date for their matched controls.

\section{Assessment of risk factors}

We assessed various medical risk factors for fracture that had previously been reported in the literature. ${ }^{45}$ Subjects were considered to have a given medical risk factor for lower limb fracture if the diagnosis was listed in their computerized medical record at any time before their index date (including historical entries recorded for the time before their practice began contributing data to the GPRD). Subjects were considered to have a road collision as a risk factor for lower limb fracture if such a diagnosis was recorded within 90 days before their index date. Half of these collisions were recorded within three weeks before the index date; $75 \%$ were recorded within one and one and a half months before the index date.

For analyses of associations between prescription drugs and lower limb fractures, subjects were considered to be currently exposed to a given therapeutic class if a prescription for any drug in that class was recorded in their computerized medical record during the 30 days before their index date. Drugs were categorized into therapeutic classes based on information published in the British National Formulary. ${ }^{6}$ In separate analyses, we evaluated exposure to drugs for which subjects had prescriptions recorded within 90 days before their index date. Because these results were generally similar to results for the analyses for prescriptions recorded within 30 days before the index date, we present only the results for the exposure period within 30 days before the index date.

\section{Statistical methods}

We estimated stratum specific incidence rates as the number of cases in a given stratum divided by the person-time contributed by subjects in the base population in that stratum, and we calculated 95\% confidence intervals using Byar's approximation. ${ }^{7}$ For the case-control analysis, we estimated the relative risk (RR) and 95\% confidence interval (CI) as hazard ratios using conditional logistic regression (PHREG procedure, SAS version 8.02, SAS Institute Inc, Cary, NC). Relative risk estimates presented here are conditional on the matching factors and adjusted for all other risk factors we studied. We considered relative risk estimates to be statistically significant if the lower 95\% confidence bound was greater than 1.00 with no adjustment for multiple comparisons. Relative risks and confidence intervals were rounded to the nearest 0.1 for presentation. Stratum specific population attributable risks were estimated as the attributable fraction among cases (calculated as $[R R-1] / R R$ ) multiplied by the proportion of cases exposed in the stratum. ${ }^{8}$ These results are expressed as percentages.

\section{RESULTS}

\section{Incidence of lower limb fractures}

We identified 32900 subjects who had a first time (incident) diagnosis of lower limb fracture recorded in the GPRD from 1 January 1990 to 31 December 2001. Table 1 presents characteristics of these subjects and the crude incidence rates of lower limb fractures by sex and by age (in decades). The incidence of all lower limb fractures combined was 17\% higher in women than in men. The age specific distribution of lower limb fracture incidence exhibited a small peak among 10-19 year olds (3.3 per 1000 person-years), a progressive
Table 1 Characteristics of subjects with first time lower limb fracture in 1990-2001 with incidence rates by sex and age

\begin{tabular}{|c|c|c|c|c|}
\hline \multirow[b]{2}{*}{ Characteristic } & \multicolumn{2}{|l|}{ Cases } & \multirow{2}{*}{$\begin{array}{l}\text { Person-years } \\
\text { (base } \\
\text { population) }\end{array}$} & \multirow{2}{*}{$\begin{array}{l}\text { Incidence per } \\
1000 \text { person- } \\
\text { years }\end{array}$} \\
\hline & No & $\%$ & & \\
\hline \multicolumn{5}{|l|}{ Sex } \\
\hline Male & 14842 & 45.1 & 5131454 & 2.9 \\
\hline Female & 18058 & 54.9 & 5381987 & 3.4 \\
\hline \multicolumn{5}{|l|}{ Age } \\
\hline $0-9$ & 2112 & 6.4 & 1310279 & 1.6 \\
\hline $10-19$ & 4206 & 12.8 & 1262174 & 3.3 \\
\hline $20-29$ & 4058 & 12.3 & 1463895 & 2.8 \\
\hline $30-39$ & 3738 & 11.4 & 1671256 & 2.2 \\
\hline $40-49$ & 3214 & 9.8 & 1505433 & 2.1 \\
\hline $50-59$ & 3462 & 10.5 & 1227903 & 2.8 \\
\hline $60-69$ & 3217 & 9.8 & 965335 & 3.3 \\
\hline 70-79 & 3774 & 11.5 & 723632 & 5.2 \\
\hline $80-89$ & 3897 & 11.8 & 327983 & 11.9 \\
\hline$\geqslant 90$ & 1222 & 3.7 & 55552 & 22.0 \\
\hline \multicolumn{5}{|l|}{ Fracture type } \\
\hline Hip & 5499 & 16.7 & - & - \\
\hline Other femur & 2673 & 8.1 & - & - \\
\hline Patella & 927 & 2.8 & - & - \\
\hline Tibia/fibula & 5675 & 17.3 & - & - \\
\hline Ankle & 7450 & 22.6 & - & - \\
\hline Tarsal/metatarsal & 5491 & 16.7 & - & - \\
\hline Phalanges & 5178 & 15.7 & - & - \\
\hline Unspecified & 7 & 0 & - & - \\
\hline
\end{tabular}

increase after age 50, and a substantially higher peak among subjects aged 90 and older (22.0 per 1000 person-years).

The most common anatomic site of lower limb fracture was the ankle $(22.6 \%$ of all incident lower limb fractures), followed by the tibia/fibula (17.3\%), the hip (16.7\%), and the tarsal/metatarsal bones (16.7\%). Fractures of the hip and other femoral sites combined made up approximately $25 \%$ of the total. Two hundred eighty eight subjects $(0.9 \%)$ had fractures at more than one lower limb site on the day their first lower limb fracture was recorded; the results we report here relate only to the first fracture listed in each subject's computerized medical record.

Figure 1 shows the incidence of lower limb fractures by sex for each age group. Lower limb fractures were more common among males than among females in the younger age groups (up to 30-39 years old). The incidence rates for 40-49 year old men and women were closely similar to each other. Among subjects 50-59 years and older, the incidence of lower limb fractures was higher in women than in men, and the difference increased with increasing age. Among the oldest age group $(\geqslant 90$ years old), the incidence of lower limb

Table 2 Characteristics of cases and controls

\begin{tabular}{|c|c|c|c|c|}
\hline \multirow[b]{2}{*}{ Characteristic } & \multicolumn{2}{|l|}{ Cases } & \multicolumn{2}{|c|}{ Controls } \\
\hline & No & $\%$ & No & $\%$ \\
\hline \multicolumn{5}{|l|}{ Sex } \\
\hline Male & 14811 & 45.1 & 29517 & 45.2 \\
\hline Female & 18016 & 54.9 & 35778 & 54.8 \\
\hline \multicolumn{5}{|l|}{ Age } \\
\hline $0-9$ & 2034 & 6.2 & 4068 & 6.2 \\
\hline $10-19$ & 4282 & 13.0 & 8556 & 13.1 \\
\hline $20-49$ & 11029 & 33.6 & 22047 & 33.8 \\
\hline $50-79$ & 10521 & 32.0 & 20920 & 32.0 \\
\hline$\geqslant 80$ & 4961 & 15.1 & 9704 & 14.9 \\
\hline \multicolumn{5}{|l|}{ Fracture sites } \\
\hline $\mathrm{Hip} / \mathrm{femur}$ & 8066 & 24.6 & - & - \\
\hline Patella/tibia/fibula & 6615 & 20.2 & - & - \\
\hline Ankle/foot & 18,146 & 55.3 & - & - \\
\hline
\end{tabular}


Table 3 Risk factors for lower limb fracture: relative risk (RR) estimates and 95\% confidence intervals (Cl)

\begin{tabular}{|c|c|c|c|c|c|c|}
\hline \multirow[b]{2}{*}{ Diagnoses* } & \multicolumn{2}{|l|}{ Cases } & \multicolumn{2}{|c|}{ Controls } & \multirow[b]{2}{*}{ RR† } & \multirow[b]{2}{*}{$95 \% \mathrm{Cl}$} \\
\hline & No & $\%$ & No & $\%$ & & \\
\hline Osteoporosis & 701 & 2.1 & 713 & 1.1 & 1.9 & 1.7 to 2.2 \\
\hline Parkinsonism & 358 & 1.1 & 347 & 0.5 & 1.9 & 1.6 to 2.2 \\
\hline Alcoholism & 850 & 2.6 & 880 & 1.4 & 1.8 & 1.7 to 2.0 \\
\hline Cataract & 1186 & 3.6 & 2117 & 3.2 & 1.1 & 1.0 to 1.2 \\
\hline Dementia & 609 & 1.9 & 533 & 0.8 & 2.3 & 2.0 to 2.6 \\
\hline Epilepsy & 582 & 1.8 & 614 & 0.9 & 1.8 & 1.6 to 2.0 \\
\hline Cancer & 973 & 3.0 & 1714 & 2.6 & 1.1 & 1.0 to 1.2 \\
\hline Obesity & 687 & 2.1 & 1158 & 1.8 & 1.1 & 1.0 to 1.3 \\
\hline Rheumatoid arthritis & 389 & 1.2 & 524 & 0.8 & 1.4 & 1.2 to 1.6 \\
\hline Osteoarthritis & 3463 & 10.6 & 6194 & 9.5 & 1.1 & 1.1 to 1.2 \\
\hline Road collision & 192 & 0.6 & 59 & 0.1 & 6.3 & 4.7 to 8.5 \\
\hline \multicolumn{7}{|l|}{ Drugsł } \\
\hline Corticosteroids & 416 & 1.3 & 591 & 0.9 & 1.3 & 1.1 to 1.5 \\
\hline Antipsychotics & 491 & 1.5 & 540 & 0.8 & 1.4 & 1.2 to 1.6 \\
\hline Antidepressants & 1263 & 3.9 & 1710 & 2.6 & 1.3 & 1.2 to 1.4 \\
\hline Hypnotics/sedatives & 1478 & 4.5 & 2306 & 3.5 & 1.1 & 1.0 to 1.2 \\
\hline \multicolumn{7}{|l|}{ Other characteristics } \\
\hline Smoker & 4576 & 13.9 & 7611 & 11.7 & 1.2 & 1.2 to 1.3 \\
\hline Ex-smoker & 1179 & 3.6 & 2166 & 3.3 & 1.1 & 1.0 to 1.2 \\
\hline Smoking unknown & 16627 & 50.7 & 34289 & 52.5 & 0.9 & 0.9 to 1.0 \\
\hline BMI $24-28 \S$ & 4600 & 14.0 & 9085 & 13.9 & 1.0 & 1.0 to 1.1 \\
\hline $\mathrm{BMI}>28 \S$ & 3242 & 9.9 & 6060 & 9.3 & 1.1 & 1.0 to 1.1 \\
\hline BMI unknown§ & 18217 & 55.5 & 36918 & 56.5 & 1.0 & 1.0 to 1.1 \\
\hline
\end{tabular}

*Diagnosis recorded at any time before index date (except for road collisions, which were recorded within 90 days before index date).

†Relative risk estimates are conditional on the matching factors (age, sex, general practice, index date, and duration of follow up in GPRD before index date) and adjusted for all other risk factors.

$\ddagger$ Any prescription for drug in therapeutic class recorded within 30 days before index date.

-Reference: non-smokers.

$\S$ Body mass index $\left(\mathrm{kg} / \mathrm{m}^{2}\right)$; reference: $\mathrm{BMI}<24$.

Table 4 Relative risk (RR) estimates for risk factors by age

\begin{tabular}{|c|c|c|c|c|c|}
\hline \multirow[b]{2}{*}{ Diagnoses* } & \multicolumn{5}{|c|}{$\mathrm{RR}+$ by age } \\
\hline & $0-9$ & $10-19$ & $20-49$ & $50-79$ & $\geqslant 80$ \\
\hline Osteoporosis & & & & 1.9 & 1.9 \\
\hline Parkinsonism & & & & 2.3 & 1.6 \\
\hline Alcoholism & & & 1.9 & 1.9 & \\
\hline Cataract & & & 3.5 & & \\
\hline Dementia & & & & 3.0 & 2.0 \\
\hline Epilepsy & & & 1.7 & 2.2 & 1.7 \\
\hline Cancer & & & & 1.2 & \\
\hline Obesity & & & 1.2 & & \\
\hline Rheumatoid arthritis & & & & 1.6 & \\
\hline Osteoarthritis & & & 1.5 & 1.2 & \\
\hline Road collision & 16.0 & 8.7 & 4.9 & 9.3 & \\
\hline \multicolumn{6}{|l|}{ Drugsf } \\
\hline Corticosteroids & & & 1.5 & 1.4 & \\
\hline Antipsychotics & & & & 1.4 & 1.4 \\
\hline Antidepressants & & & 1.3 & 1.2 & 1.5 \\
\hline Hypnotics/sedatives & & & & 1.2 & \\
\hline \multicolumn{6}{|l|}{ Other characteristics } \\
\hline Smoker & & & 1.2 & 1.2 & \\
\hline Ex-smoker & & & & 1.2 & \\
\hline Smoking unknown & & & & & \\
\hline BMI $24-28 \S$ & & & 1.2 & & \\
\hline $\mathrm{BMI}>28 \S$ & & & 1.4 & & \\
\hline BMI unknown§ & & & 1.1 & & \\
\hline
\end{tabular}

Data are presented only for those risk factors and age groups for which the lower confidence bound of the relative risk estimate was greater than 1 .

*Diagnosis recorded at any time before index date (except for road collisions, which were recorded within 90 days before index date). tRelative risk estimates are conditional on the matching factors (age, sex general practice, index date, and duration of follow up in GPRD before index date) and adjusted for all other risk factors.

$\ddagger$ Any prescription for drug in therapeutic class recorded within 30 days before index date.

-Reference: non-smokers.

§Body mass index $\left(\mathrm{kg} / \mathrm{m}^{2}\right)$; reference: $\mathrm{BMI}<24$. fractures was approximately twice as high in women as in men.

Within age groups, the proportions of fractures that occurred at different anatomic sites in the lower limb were generally similar between males and females (fig 2). For example, the tibia and fibula were the most common sites of lower limb fractures among both boys and girls aged 0-9, accounting for more than $40 \%$ of lower limb fractures in each sex. By contrast, fractures of the hip were rare in this age group. In older age groups (10-59 years old), fractures of the ankle, tarsal and metatarsal bones, and phalanges of the foot represented higher proportions of lower limb fractures than in children. In the oldest age groups (age 70 and older), fractures of the hip predominated among lower limb fracture sites, comprising approximately equal proportions of all lower limb fractures among men and women. Hip and other femoral fractures comprised the majority of all lower limb

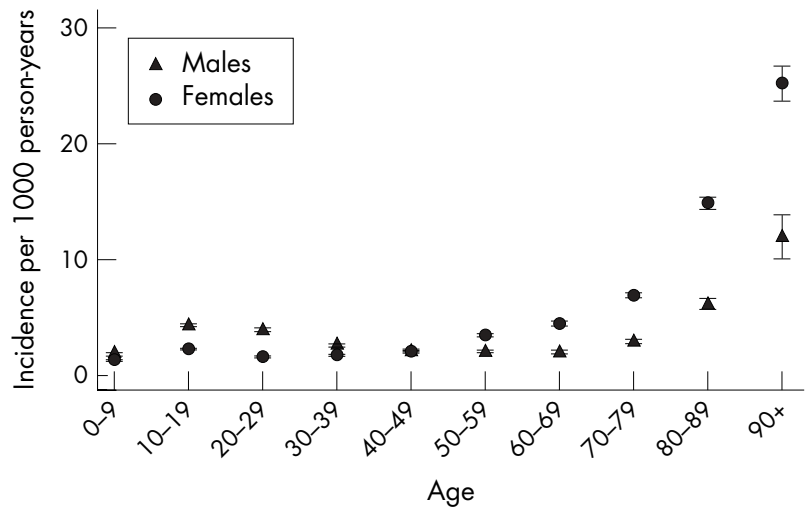

Figure 1 Incidence of lower limb fracture by sex for each age group. 

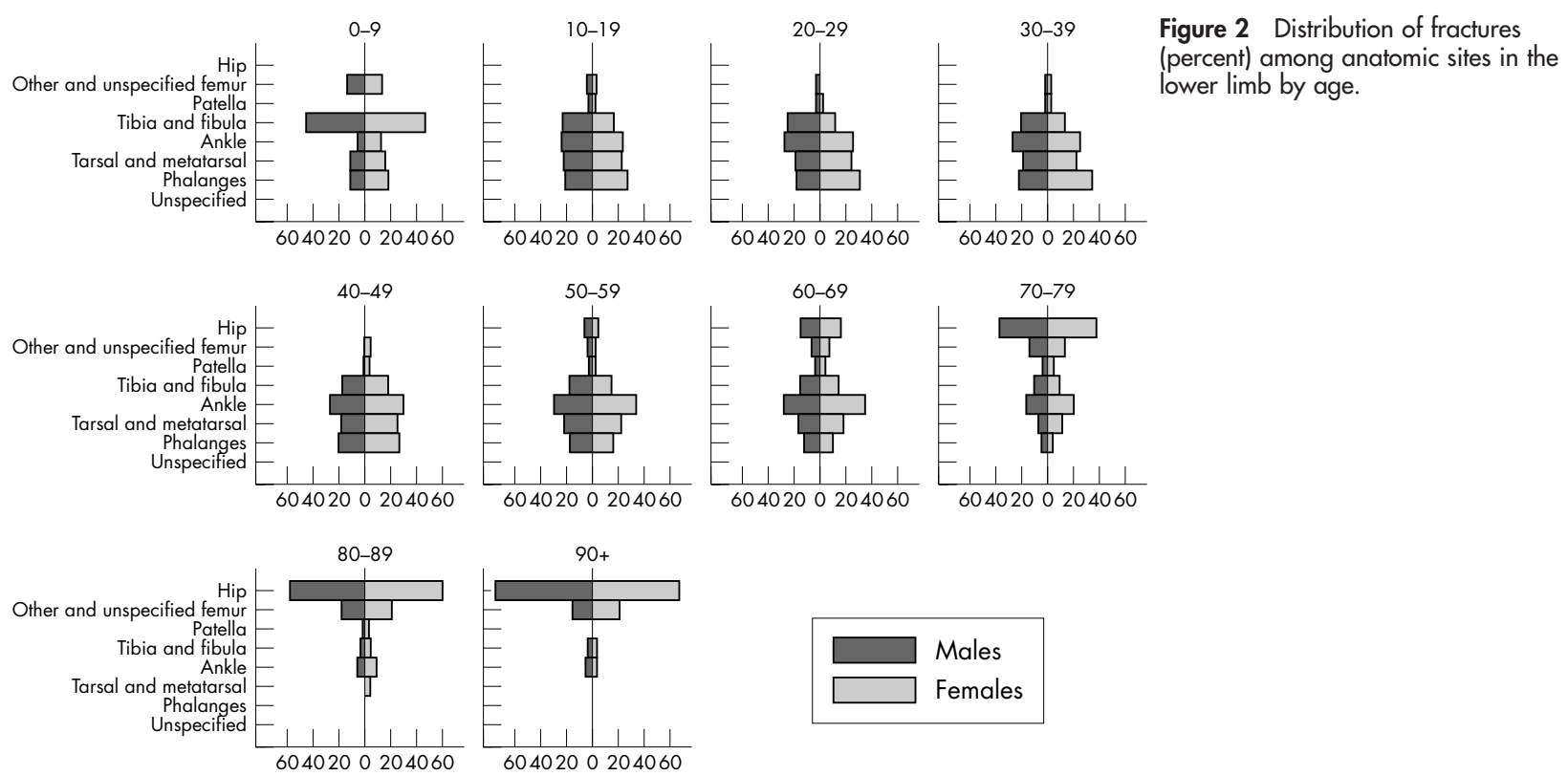

fractures among both men and women 80 years of age and older.

\section{Case-control evaluation of risk factors}

We carried out a case-control evaluation of several medical diagnoses and therapeutic drug classes that have previously been reported to be risk factors for fractures. Up to two controls were matched to 32827 cases by sex, age (within one year), general practice, index date, and duration of follow up in the GPRD before the index date (within one year). We combined subjects into five age groups and three fracture sites for the case-control analyses. Characteristics of the cases and controls are listed in table 2. All controls were drawn from the same general practice as the case to which they were matched. For all controls, the difference in duration of follow up in the GPRD between the control and the case to which they were matched was less than one year (data not shown). For all controls, the index date used to evaluate the presence or absence of risk factors was the same date as for the case to which they were matched (that is, the date on which the case's first time lower limb fracture was recorded).

Summary estimates of relative risk in the whole study population for each diagnostic category and drug class are listed in table 3. The largest relative risk estimate observed was for road collisions (RR 6.3, 95\% CI 4.7 to 8.5). Among medical risk factors, the largest relative risk estimates were observed for dementia, osteoporosis, parkinsonism, alcoholism, and epilepsy. It should be noted that some of the relative risk estimates, although "statistically significant", are only slightly above 1.00. Also, some of the relative risk estimates that are close to 1.00, although "significantly" increased, may be due to chance or to residual confounding. We adjusted all analyses for smoking and body mass index, and estimates for these variables are also presented in table 3 .

In stratified analyses, relative risk estimates differed materially between the sexes only for road collisions (RR 7.7, 95\% CI 5.3 to 11.3 in men and $4.7,95 \%$ CI 2.9 to 7.4 in women).

Relative risk estimates varied considerably by age. Table 4 lists the statistically significant relative risk estimates by age. Most risk factors (with the exception of road collisions) were more prominent among older subjects. Many factors were also associated with significantly increased risk of lower limb fracture among 20-49 year olds. Road collisions were the only risk factor we studied that was significantly associated with lower limb fractures among 0-9 and 10-19 year olds. It should be noted that the larger size of the 20-49 and 50-79 year old groups contributes to several relative risk estimates that are close to 1.00 being "significantly" raised.

Table 5 lists the relative risk estimates and population attributable risk percentages for the statistically significant age specific risk factors associated with each of the 3 categories of lower limb fracture (hip/femur, patella/tibia/ fibula, and ankle/foot).

Most risk factors accounted for fewer than 5\% of lower limb fractures of a particular lower limb site in any age group. The only risk factors with population attributable risk estimates that exceeded 5\% were dementia (for hip and femur fractures among subjects 80 years and older) and smoking (for hip and femur fractures among 50-79 year olds). Dementia was also an important risk factor for hip and femur fractures among 50-79 year olds (population attributable risk 3.9\%). Raised population attributable risks associated with the "unknown" smoking and body mass index categories were partially a result of the substantial proportion of the population with unknown values for these variables. The largest population attributable risk associated with any of the drug therapeutic classes was 3.0\% for hip and femur fractures among subjects 80 years and older.

\section{DISCUSSION}

To our knowledge, this is the first large population based study carried out using data from the United Kingdom in which the relative importance of various medical risk factors for lower limb fracture has been studied quantitatively. By "population based" we mean that the study population is representative of the age and sex distribution of the general population of the United Kingdom and that the cases and controls are drawn from a large number of general practices located in various regions throughout the country rather than from a specific referral center or geographical location. We used a nested matched case-control design for our study rather than a cohort analysis in order to increase the efficiency of the study for estimating relative risks and to maximize the control of potential confounding due to the 
Table 5 Relative risk (RR) and population attributable risk percentages for risk factors by fracture site and age group*

\begin{tabular}{|c|c|c|c|c|c|c|}
\hline \multirow[b]{2}{*}{ Risk factor } & \multirow[b]{2}{*}{ Fracture site } & \multirow[b]{2}{*}{ Age group } & \multirow[b]{2}{*}{$\mathbf{R R} \dagger$} & \multicolumn{2}{|c|}{ Cases exposed } & \multirow{2}{*}{$\begin{array}{l}\text { Population attributable risk } \\
(\%)\end{array}$} \\
\hline & & & & No & $\% \ddagger$ & \\
\hline \multirow[t]{4}{*}{ Osteoporosis } & $\mathrm{Hip} /$ femur & $50-79$ & 2.5 & 185 & 6.2 & 3.7 \\
\hline & Hip/femur & $\geqslant 80$ & 2.0 & 293 & 7.2 & 3.6 \\
\hline & Patella/tibia/fibula & $50-79$ & 1.6 & 44 & 2.4 & 0.9 \\
\hline & Ankle/foot & $50-79$ & 1.4 & 119 & 2.1 & 0.6 \\
\hline \multirow[t]{3}{*}{ Parkinsonism } & $\mathrm{Hip} /$ femur & $50-79$ & 3.7 & 135 & 4.5 & 3.3 \\
\hline & $\mathrm{Hip} / \mathrm{femur}$ & $\geqslant 80$ & 1.7 & 171 & 4.2 & 1.7 \\
\hline & Patella/tibia/fibula & $\geqslant 80$ & 2.6 & 17 & 5.0 & 3.1 \\
\hline \multirow{5}{*}{ Alcoholism } & $\mathrm{Hip} /$ femur & $50-79$ & 2.6 & 149 & 5.0 & 3.1 \\
\hline & Patella/tibia/fibula & $20-49$ & 2.0 & 101 & 4.1 & 2.1 \\
\hline & Patella/tibia/fibula & $50-79$ & 2.2 & 63 & 3.5 & 1.9 \\
\hline & Ankle/foot & $20-49$ & 1.9 & 308 & 3.8 & 1.8 \\
\hline & Ankle/foot & $50-79$ & 1.5 & 170 & 3.0 & 0.9 \\
\hline \multirow[t]{3}{*}{ Cataract } & Patella/tibia/fibula & $20-49$ & 6.8 & 7 & 0.3 & 0.2 \\
\hline & Ankle/foot & $20-49$ & 3.1 & 16 & 0.2 & 0.1 \\
\hline & Ankle/foot & $50-79$ & 1.3 & 169 & 3.0 & 0.7 \\
\hline \multirow[t]{2}{*}{ Dementia } & $\mathrm{Hip} /$ femur & $50-79$ & 4.6 & 151 & 5.0 & 3.9 \\
\hline & $\mathrm{Hip} /$ femur & $\geqslant 80$ & 2.2 & 408 & 10.0 & 5.4 \\
\hline \multirow{6}{*}{ Epilepsy } & $\mathrm{Hip} /$ femur & $20-49$ & 4.0 & 13 & 2.9 & 2.2 \\
\hline & Hip/femur & $50-79$ & 3.3 & 107 & 3.6 & 2.5 \\
\hline & Hip/femur & $\geqslant 80$ & 1.6 & 74 & 1.8 & 0.7 \\
\hline & Ankle/foot & $20-49$ & 1.7 & 151 & 1.9 & 0.7 \\
\hline & Ankle/foot & $50-79$ & 1.9 & 102 & 1.8 & 0.8 \\
\hline & Ankle/foot & $\geqslant 80$ & 3.7 & 10 & 1.9 & 1.4 \\
\hline Cancer & $\mathrm{Hip} / \mathrm{femur}$ & $50-79$ & 1.7 & 256 & 8.5 & 3.6 \\
\hline Obesity & Patella/tibia/fibula & $20-49$ & 1.5 & 49 & 2.0 & 0.7 \\
\hline \multirow{2}{*}{ Rheumatoid arthritis } & $\mathrm{Hip} /$ femur & $50-79$ & 2.4 & 129 & 4.3 & 2.5 \\
\hline & Patella/tibia/fibula & $50-79$ & 1.9 & 45 & 2.5 & 1.2 \\
\hline \multirow[t]{4}{*}{ Osteoarthritis } & $\mathrm{Hip} /$ femur & $50-79$ & 1.2 & 648 & 21.6 & 3.7 \\
\hline & Patella/tibia/fibula & $20-49$ & 1.9 & 33 & 1.4 & 0.6 \\
\hline & Ankle/foot & $20-49$ & 1.4 & 110 & 1.4 & 0.4 \\
\hline & Ankle/foot & $50-79$ & 1.2 & 973 & 17.0 & 2.7 \\
\hline \multirow[t]{7}{*}{ Road collisions } & $\mathrm{Hip} /$ femur & $20-49$ & 14.1 & 15 & 3.3 & 3.1 \\
\hline & Patella/tibia/fibula & 10-19 & 28.9 & 14 & 1.3 & 1.3 \\
\hline & Patella/tibia/fibula & $20-49$ & 14.7 & 37 & 1.5 & 1.4 \\
\hline & Patella/tibia/fibula & $50-79$ & 12.5 & 21 & 1.2 & 1.1 \\
\hline & Ankle/foot & $10-19$ & 3.3 & 12 & 0.4 & 0.3 \\
\hline & Ankle/foot & $20-49$ & 2.6 & 37 & 0.5 & 0.3 \\
\hline & Ankle/foot & $50-79$ & 5.8 & 21 & 0.4 & 0.3 \\
\hline \multirow[t]{2}{*}{ Corticosteroids } & $\mathrm{Hip} / \mathrm{femur}$ & $50-79$ & 1.5 & 119 & 4.0 & 1.3 \\
\hline & Ankle/foot & 50-79 & 1.3 & 87 & 1.5 & 0.4 \\
\hline Antipsychotics & $\mathrm{Hip} /$ femur & $50-79$ & 2.5 & 117 & 3.9 & 2.3 \\
\hline & Hip/femur & $\geqslant 80$ & 1.5 & 240 & 5.9 & 2.0 \\
\hline Antidepressants & $\mathrm{Hip} / \mathrm{femur}$ & $50-79$ & 1.5 & 237 & 7.9 & 2.8 \\
\hline & Hip/femur & $\geqslant 80$ & 1.5 & 357 & 8.7 & 3.0 \\
\hline & Ankle/foot & $20-49$ & 1.3 & 209 & 2.6 & 0.6 \\
\hline Hypnotics/sedatives & $\mathrm{Hip} /$ femur & $20-49$ & 2.9 & 16 & 3.5 & 2.3 \\
\hline & Ankle/foot & $50-79$ & 1.2 & 282 & 4.9 & 0.7 \\
\hline Smoker & $\mathrm{Hip} /$ femur & $50-79$ & 1.5 & 483 & 16.1 & 5.5 \\
\hline & $\mathrm{Hip} /$ femur & $\geqslant 80$ & 1.2 & 231 & 5.6 & 1.0 \\
\hline & Ankle/foot & $20-49$ & 1.3 & 1892 & 23.3 & 5.2 \\
\hline & Ankle/foot & $50-79$ & 1.1 & 953 & 16.6 & 2.0 \\
\hline Ex-smoker & Ankle/foot & $50-79$ & 1.2 & 396 & 6.9 & 1.2 \\
\hline Smoking unknown & $\mathrm{Hip} /$ femur & $50-79$ & 1.3 & 1,284 & 42.9 & 9.0 \\
\hline BMI 24-28 & Ankle/foot & $20-49$ & 1.2 & 1366 & 16.8 & 2.9 \\
\hline & Ankle/foot & $50-79$ & 1.2 & 1342 & 23.4 & 3.8 \\
\hline $\mathrm{BMI}>28$ & Ankle/foot & $20-49$ & 1.5 & 998 & 12.3 & 3.9 \\
\hline & Ankle/foot & $50-79$ & 1.3 & 1155 & 20.2 & 4.3 \\
\hline BMI unknown & Patella/tibia/fibula & $20-49$ & 1.2 & 1305 & 53.5 & 9.1 \\
\hline
\end{tabular}

matching factors (age, sex, general practice, duration of follow up, and calendar time).

Our data confirm that there is considerable variation in the incidence of lower limb fractures by age and sex. The higher crude incidence of lower limb fractures among women than among men is due to the increasing incidence of lower limb fractures with increasing age, the higher age specific rates of lower limb fracture among older women than older men, and the preponderance of women surviving into the older age groups. Within most age groups, the distribution of fractures among various sites in the lower limb is similar among men to the distribution among women.

We have reported population attributable risk estimates for the association between various medical risk factors and specific categories of lower limb fracture. Population attributable risk is an epidemiologic measure that combines information on the magnitude of the relative risk estimate and the prevalence of a particular risk factor among cases in 
the population. Assuming that the relative risk estimates we observed are causal (that is, that there was no important unmeasured confounding), these population attributable risk estimates represent the percentage of cases of the specific fracture type among a given age group that are due to a particular risk factor and would theoretically be prevented if exposure to that risk factor could be eliminated.

We found that dementia among subjects 80 years and older and smoking among subjects 50-79 years old each accounted for more than $5 \%$ of hip and femur fractures in these age groups, but other risk factors accounted for smaller population attributable risk percentages for various fracture types in these and other age groups.

Our estimates of the sex specific and age specific incidence of lower limb fractures in the United Kingdom are broadly compatible with those reported by van Staa et al. ${ }^{4}$ These authors used data from a larger number of practices contributing to the GPRD than we did; their method of estimating person-time differed from ours; and they did not study fractures in subjects younger than 20 years old. Calculated from information presented in their table 1 , the age standardized incidence rates of lower limb fractures were 3.4 per 1000 person-years in men (compared with 2.9 per 1000 person-years in our study) and 4.5 per 1000 personyears in women (compared with 3.4 per 1000 person-years in our study). The sex specific and age specific pattern of lower limb fracture incidence we observed-namely, a higher incidence of lower limb fractures among men through the first four decades of life and a higher incidence among women older than 50-is also similar to the sex specific, age standardized pattern reported for all fractures by van Staa et al. It should be noted that age standardization would have a negligible effect on the findings we have reported because the population included in the GPRD has a similar age and sex distribution to that of the UK.

In a later study, van Staa et al estimated relative risks for fracture associated with various diagnoses and drug exposures and developed a risk prediction model for the occurrence of osteoporotic fractures. ${ }^{9}$ Their analysis differs from ours in that they did not consider alcoholism or trauma as potential risk factors, and their definition of current drug use (any prescription within six months before the index date) was broader than ours (any use within 30 days before the index date). Conversely, we did not evaluate several risk factors they identified (such as anemia and chronic obstructive pulmonary disease).

Fitzpatrick et al reported that osteoporotic indices (including measurement of bone mineral density) did not differ significantly between 89 cases of hip fracture in women over age 50 and their age matched controls. ${ }^{10}$ In their study, subjects with cancer, major trauma, fractures at other sites, or moderate to severe cognitive impairment were excluded. We found that diagnosed osteoporosis was significantly associated with the risk of lower limb fractures (RR 1.9, 95\% CI 1.7 to 2.2) and was an important predictor for hip and femur fracture in the elderly (population attributable risk $3.7 \%$ among $50-79$ year olds and $3.6 \%$ among subjects 80 years and older). An important difference between the two studies is that in our study osteoporosis was considered present if diagnosed clinically at any time before the index date. Such a diagnosis may have been prompted by fractures at other sites that were not part of our study (for example, the vertebrae), and may therefore reflect the presence of more severe osteoporosis than indicated by the $x$-ray osteoporotic indices used by Fitzpatrick et al.

A limitation of any study of risk factors for a condition such as lower limb fractures is that not all risk factors can possibly be included and that the risk factors that are included are conceptualized in a manner that ultimately is

\section{Key points}

- During the period 1990-2001 in the United Kingdom, lower limb fractures occurred with an overall incidence of approximately 3.4 per 1000 person-years in women and 2.9 per 1000 person-years in men.

- Incidence rates varied widely by age and fracture type, but the distribution of fracture types was generally similar for men and women within age groups.

- Among the many risk factors for lower limb fracture that have been identified, road collisions are associated with the highest relative risk but account for only $3.1 \%$ or less of the population attributable risk in any age group.

- Among medical risk factors, dementia accounted for the highest population attributable risk for femur fractures among people aged 80 years and older $(5.4 \%)$, while smoking was the most important risk factor we evaluated among 50-79 year olds (population attributable risk 5.5\%).

- Because there are many risk factors for lower limb fracture, prevention programs must be multifactorial in their approach.

somewhat arbitrary. Our study was limited to information on risk factors that would be routinely recorded in a medical record. We did not assess such potential risk factors as driver distraction (for example, due to cell phone use or passenger smoking), which could be an indirect cause of lower limb fractures by increasing the risk of road collisions. Moreover, certain risk factors we studied might be categorized differently by other investigators; for example, the risk of fracture related to use of an antiparkinsonism drug could be evaluated separately from the risk of parkinsonism itself. As another example, inclusion of anemia as a distinct risk factor might decrease the relative risk observed for rheumatoid arthritis if some of the risk related to rheumatoid arthritis is mediated through the development of anemia. We did not have information on calcium intake or activity level, which have previously been reported to be risk factors for hip fracture. ${ }^{11}$ Therefore, the relative risk estimates and population attributable risks that we report must be interpreted in the context of the constellation of medical risk factors we studied. Moreover, it is likely that different relative and population attributable risk estimates would be obtained for at least some of the medical risk factors we studied if our case definition included only lower limb fractures of a particular severity (for example, those requiring surgical intervention).

Our findings emphasize that a multifactorial approach to the prevention of lower limb fractures is necessary if the incidence of these fractures is to be reduced through medical or public health interventions. For example, smoking cessation, weight loss, and decreased use of various classes of medications might all contribute to a decreased risk of specific lower limb fractures among certain age groups. The data we have presented here on the population burden of lower limb fractures and population attributable risks may be useful to public health program planners in prioritizing funding for the prevention of lower limb fractures as well as for developing approaches to the prevention of lower limb fractures in specific segments of the population.

\section{ACKNOWLEDGEMENTS}

This study was funded by a grant from AstraZeneca. We thank Saga Johansson, Mari-Ann Wallender, and Susan S Jick for helpful 
comments on an earlier draft of the manuscript, and we are indebted to the general practitioners who contribute information to the GPRD for their continuing effort and cooperation.

\section{Authors' affiliations}

J A Kaye, H Jick, Boston Collaborative Drug Surveillance Program, Boston University School of Medicine, Lexington, Massachusetts, USA

\section{REFERENCES}

1 Jick H, Jick SS, Derby LE. Validation of information recorded on general practitioner based computerized data resource in the United Kingdom. BMJ 1991;302:766-8

2 Jick SS, Kaye JA, Vasilakis-Scaramozza C, et al. Validity of the general practice research database. Pharmacotherapy 2003;23:686-9.

3 Meier CR, Schlienger RG, Kraenzlin ME, et al. HMG-CoA reductase inhibitors and the risk of fractures. JAMA 2000;283:3205-10.
4 van Staa TP, Dennison EM, Leufkens HGM, et al. Epidemiology of fractures in England and Wales. Bone 2001;29:517-22.

5 Woolf AD, Åkesson K. Preventing fractures in elderly people. BMJ 2003;327:89-95

6 British Medical Association and Royal Pharmaceutical Society of Great Britain. British national formulary. 44th Ed. London: BMA/Royal Pharmaceutical Society, September, 2002.

7 Rothman KJ, Boice JD Jr. Epidemiologic analysis with a programmable calculator, NIH Publication 79-1649. Washington, DC: US Government Printing Office, 1979

8 Rothman KJ. Epidemiology: an introduction. New York, NY: Oxford University Press, 2002.

9 van Staa TP, Leufkens HGM, Cooper C. Utility of medical and drug history in fracture risk prediction among men and women. Bone 2002;31:508-14.

10 Fitzpatrick P, Kirke PN, Daly L, et al. Predictors of first hip fracture and mortality post fracture in older women. Ir J Med Sci 2001;170:49-53.

11 Cooper C, Barker DJ, Wickham C. Physical activity, muscle strength, and calcium intake in fracture of the proximal femur in Britain. BMJ 1988;297:1443-6.

\section{LACUNAE}

\section{Cruise control blamed for $190 \mathrm{~km} / \mathrm{h}$ drive-legal action follows}

A driver was said to have had his life saved by his mobile phone. Initial reports said that the driver had overtaken a truck on the A7l freeway in central France and that the car's cruise control had stuck at $191 \mathrm{~km} / \mathrm{h}$. The driver had called the police in panic about the car being out of his control and spoken to them for an hour as he sped south. Reports quoted the police as saying that eventually they were able to calm the frightened man and that eventually he was able to cut the engine and roll to a stop $20 \mathrm{~km}$ north of a toll plaza that had been evacuated. Three days later car manufacturer Renault said that the Vel Satis MPV vehicle showed no signs of malfunction and is seeking legal redress to protect its reputation. The car will be tested by a third party and Renault have not ruled out suing for damages (reported by AFP October 2004; contributed by Ian Scott).

\section{Head protection for young soccer players}

The New York State West Soccer Association, overseeing about 80000 youth players in western New York, is expected to announce that headgear will be mandatory next spring for players under 14. Altogether 35000 kids will be required to cover their foreheads to get into games. Omer Doron, association executive director, says he's not aware of any soccer body making headgear mandatory "and we're happy to be the first". FIFA, soccer's top governing body, has specified only that acceptable headgear not include hard surfaces, sharp edges, or loose straps. Obviously, the US market is potentially huge-about 12.4 million kids aged 617 play soccer, and the sport trails only basketball in popularity. One company claims says it has sold 100000 models and had 11 players using the gear in Olympic soccer in Athens and four players use it in Major League Soccer. NYSWSA's Doron says the use of headgear by elite players will change things: "That's living proof that headgear doesn't change the game" (from USA Today, October 2004; contributed by Anara Guard). 